Most international authorities who organize sporting events lay down rules as to what is meant by a drug. Thus the International Olympics Committee on Doping has issued lists of groups of drugs and has defined dopirg as folows:

"Doping is the administration to, or the use by, a competing athlete of any substance foreign to the body or of any physiological substance taken in abnormal quantity or taken by an abnormal route of entry into the body, with the sole intention of increasing in an artificial and unfair manner his performance in competition. When necessity demands medical treatment with any substance which, because of its nature, dosage, or application is able to boost the athlete's performance in competition in an artificial and unfair manner, this too is to be regarded as doping."

It appears that for various reasons the International Olympics Committee has shifted responsibility to the competency of the various international sports associations. This has meant that different interpretations of the doping problem have resulted. Thus the International Cycling Union is reputed to allow the use of ephedrine.

The Concise Oxford Dictionary defines a drug as "an original simple medicinal substance, organic or inorganic, used alone or as an ingredient." Any substance naturally present in a foodstuff and taken in normal physiological amounts cannot, by any stretch of the imagination, be considered a medicinal substance. However, when many times the normal amount is proposed, and if it is given with the express purpose of improving, or attempting to improve, performance the question may reasonably be asked whether this constitutes "doping"- that is, the administration of a drug.

The Medicines Act has defined a "medicinal product." Under Section (e) the definition in general of a medicinal product, other than in treating disease is: "otherwise preventing or interfering with the normal operation of a physiological functon, whether premanently or temporarily, and whether by way of terminating, reducing or postponing or increasing or accelerating the operation of that function, or in any other way." The use of vitamins in excessive quantity as medication would therefore constitute a medicinal product and by this definition be a drug. However, it may be difficult to say what is an excessive quantity. Moreover a competitor who gives himself an unphysiological quantity of a substance like glucose, say $100 \mathrm{~g}$, believing it will improve his performance cannot reasonably be said to be doping himself. It appears therefore, Sir, difficult to say where nutrition ends and doping begins-if indeed it does when normal nutrients are concerned. -I am, etc.,

IVAN M. SHARMAN

Dunn Nutritional Laboratory,

Cambridge

1 Sharman. I. M. Darn. M. G. and Sen, R. N., British fournal of Nutrition, 1971, 26. 265. Prskop, L. Fournal of Sports Medicine and
Physical Fitness, 1965, 588 .

Pollution in the Operating Theatre

SIR,-The text of your leading article "Pollution in the Operating Theatre" (15 April, p. 123) does scant justice to the scope of its title. Polluted with anaesthetic gases the operating theatre may be, but the frequency with which wound infections occur in all theatres suggests bacterial pollution is the most compelling argument for a more logical system of theatre ventilation. ${ }^{2}$

As it happens, the answer to both concentrations of bacteria at the incision and anaesthetic gases at the anaesthetist already exists in the laminar/linear air-flow system of ventilation. The anaesthetist needs therefore to stimulate his surgical colleagues to examine critically this ventilation system, the introduction of which into our operating theatres will benefit all who participate in the surgical act: the surgeon, the anaesthetist, and not least, the patient.-I am, etc.,

Charles C. ScotT

Department of Bacteriology.

University of Dundee,

Scott, C. C. Sanderson, J. T., Guthrie, T. D., Lancet, $1971,11288$.

2 Scott, C. C., Lancet, 1971, 2, 1148.

Rh-sensitization and Third Stage of Labour

SIR,-Mr. O. A. Ladipo (18 March, p. 721) draws attention to the possibility that rhesus sensitization is to some exient an iatrogenic phenomenon. By interference with nature's management of the third stage of labour, particularly by early clamping of the placental end of the severed cord, it could be that doctors and midwives cause more potentially sensitizing fetal cells to enter the maternal cirzulation.

The value of his paper, however, is limited by the lack of orientation to other published work on the subject. A study ${ }^{1}$ with the Kleihauer technique covered 230 cases in which conventional cord clamping was compared with a technique allowing the placental end of the severed cord to drain freely. The difference between the means for fetomaternal haemorrage on a "+" score system was not significant. A later study ${ }^{2}$ of 22 patients compared early clamping with late clamping 3-10 mins after delivery, and recorded feto-maternal bleeding in six early clamping cases and seven late clamping cases. Terry $^{3}$ studied 125 patients, comparing placental delivery by "controlled cord traction" with a technique of early cutting of the cord followed by free drainage of the placental end. He found 45 out of 67 controlled cord traction cases with transplacental bleeding as opposed to 27 of 58 managed by free drainage. In a recent review ${ }^{4}$ of 200 cases in 110 of which the placental end of the cord was clamped at severance performed after cessation of cord pulsation while in 90 severance was performed at the same time but the placental end was left to bleed freely, no difference in feto-maternal transfusion could be demonstrated.

Various criticisms could be levelled at all of these studies, none of which involved precisely the same comparisons. Viewed together with Mr. Ladipo's analysis of 200 cases divided into three categories they point to a situation which calls for assessment on a wider scale than has been carried out hitherto.

The study of factors influencing fetomaternal haemorrage in relation to management of the umbilical cord in the third stage of labour occupies a tiny but very clearly defined position on the medical scene. In this letter I refer to the five papers on the subject of which I am aware, each in English in readily accessible journals and not published simultaneously. Paper 2 makes no reference to paper 1 , paper 3 refers to neither 1 nor 2, paper 4 refers to 3 only while Mr. Ladipo's paper, number 5 in sequence, refers to 3 though including an uninformative mention of paper 2. The moral probably is that the problems of scientific communication in the present day are many but that nothing is more important than the choice of title for a paper, with its indexing consequences. - I am, etc.,

J. S. ScotT

Department of Obstetrics and Gynaecology,

University of Leeds

1 Scott, J. S. Finn, R., Miller, J., and Thomas, P., American fournal
cology, $1963,85.380$.

2 Dunn, P. M., and Fraser, I. D., and Raper, A. B., Fournal of Obstetrics and Gynaecology of .

cology of the British Commonwealth, 1970, 77, 129.

Kjersgaard Johansen, J., Schacke, E., and Stürup, A. G., Acta Obstetricia et Gynecologica Scan-
dinavica, 1971, 50, 193 .

\section{Computer-aided Diagnosis of Acute Abdominal Pain}

SIR,-The report by Mr. F. T. de Dombal and his colleagues is of great interest and value (1 April, p. 9). Clinicians must welcome a computer diagnosis system in a field in which diagnosis is notoriously inaccurate. I believe that the rate of inaccurate clinical diagnosis in the series described is rather higher than may appear. "Non-specific abdominal pain" is hardly a diagnosis. In this group comprising $49 \%$ of patients it is very likely that there were, for example, a few genuine cases of appendicitis which settled without operation but which, if they had been operated upon, would have shown sufficient evidence of disease for reclassification as acute appendicitis. I could suggest other possibilities of this type, and perhaps calculations based strictly on diagnosis proved at operation would be more accurate.

It surprises me that the writers find the number of "possible disorders" so small, with only $2.6 \%$ of miscellaneous cases. Where, for example, are the ruptured physiological cysts of the right ovary, and tubal conditions which surgeons may diagnose as appendicitis, the acute mesenteric adenitis mimicking appendicitis, and the colonic obstructions due to carcinoma?

Some years ago I reviewed 1,179 emergency abdominal operations and listed $161(15 \%)$ as involving uncommon or rare conditions. ${ }^{1}$ Some of these conditions have specific signs or symptoms, the significance of which is often appreciated only in retrospect. I would hope that a computer fed with additional data would help to elucidate these rare conditions preoperatively.

There is no mention in this article of the use of the plain film of the abdomen in diagnosis. It is my firm belief that this adds to the accuracy of diagnosis. In the Leeds series the relatively low clinical diagnosis rate for perforated duodenal ulcer would probably be raised if routine $x$-rays were taken. Should not radiographic information be utilized in the computer system?

Such criticisms do not detract from the value of this paper. It is impressive, for example, to find a clinical diagnosis rate of $50 \%$ raised to $100 \%$ by the computer for 
acute diverticular disease. This is of great practical value.-I am, etc.,

JOHN A. SHEPHERD

Liverpool 1 1 Shepherd, J. A., Surgery of the Acute Abdomen, Appendix. p. 1204

\section{Breast-milk Jaundice and the Pill}

SrR,-Drs. Y. K. Wong and B. S. B. Wood (13 November, p. 403) purported to show relationship between maternal oral contraception ("the pill") and subsequent jaundice in breast-fed infants-confusingly referred to as "breast-milk jaundice" (a term best reserved for instances where there evidence that the breast milk does indeed contain a factor inhibiting conjugation of bilirubin). 1 They gave no time relationship between cessation of pill-taking and conception; the implication was that previous pill-taking, however distant in time and of as short a duration as one month, was related to the subsequent neonatal jaundice. The authors have not set out their data for the mothers of non-jaundiced infants. Other centres were invited to record their data and we would like to do so.

Records for the four years 1968-71 inclusive were used to obtain the names of all neonates clinically considered to be jaundiced during the first 10 days of life; each such infant had had a serum bilirubin determination routinely performed and the results were available to us. A serum bilirubin in excess of $10 \mathrm{mg} / 100 \mathrm{ml}$ was chosen for inclusion; infants of low birth weigh ( $<2 \mathrm{~kg})$, sick infants, and those with a positive direct Coombs test were excluded. One hundred and twenty fulfilled these criteria. Questionnaires were then sent to the mothers concerned, asking about prior oral contraception, and in particular its duration and the time lapse between cessation and conception. Eighty-two replies were received. An identical questionnaire was completed by 82 mothers of comparable but nonjaundiced infants born sequentially during early 1972. The results are shown in Tables I and II.

TABLE I-Faundiced Infants

\begin{tabular}{l|c|c|c}
\hline Mother/infant & Breast-fed & Bottle-fed & Total \\
\hline Pill & 15 & 9 & 24 \\
\hline No pill & 23 & 35 & 58 \\
\hline Total & 38 & 44 & 82 \\
\hline
\end{tabular}

TABLE II-Non-jaundiced Infants

\begin{tabular}{l|c|c|c}
\hline Mother/infant & Breast-fed & Bottle-fed & Total \\
\hline Pill & 8 & 12 & 20 \\
\hline No pill & 25 & 37 & 62 \\
\hline Total & 33 & 49 & 82 \\
\hline
\end{tabular}

The incidence of breast feeding and pre vious maternal oral contraception (15/82) within the group of jaundiced infants does not differ from that expected by chance $\left(\chi^{2}\right.$ (Yates correction) $=2.07 ; p>0.13$ ). Similar results were obtained in the non-jaundiced group ( $\chi^{2}$ (Yates correction) $=0.06 ; \mathrm{p}>0.80$ ). When the two sets of data were compared directly no significant difference was found between the distributions in the four cata- gories-that is, there was a similar incidence of breast feeding and pill-taking in the jaundiced and non-jaundiced groups. Likewise no significant difference was shown if data were used only from mothers who took oral contraceptives within six months of conception.

However, the incidence of pill-taking by mothers of jaundiced infants who were breast-fed in the Birmingham series (33/47) is significantly greater $(p<0.01$ than that in this series $(15 / 38)$. The explanation for this finding is obscure, but it may reflect a greater overall incidence of pill-taking in Birmingham.

We have, therefore, been unable to substantiate the authors' claim to have established a relationship between prior maternal oral contraception and jaundice in breastfed neonates.-We are, etc.,

Department of Gastoenterology

David Barnardo

Children's Department

IAN STOTHERS

Operational Research

MaXWell Sharratt

London Hospital

London E.1 1 Gartner, L. M., and Arias, I. M., fournal of

\section{Unplanned Pregnancy}

SIR,-Your leading article on this subject (8 April, p. 65) recommends still further education in sex. When will we ever learn? For never in the whole field of human history has so much been spoken so freely and so openly, or for so long, on so singular a subject as sex is now. To deny this is merely foolish

Yet in spite of this unwanted pregnancies continue not to decline but to escalate. Clearly there is something wrong somewhere. It seems to me that education itself may well be one of the factors, especially if it is wrong education, as much of the current propaganda would seem to be. A big rethink of the whole of the physiology of sexual behaviour in man and animals would seem to be indicated.-I am, etc.,

Chalfont St. Peter,

T. RUSSELI Bucks

\section{Deputizing Arrangements}

SIR,-I shall be grateful if you will allow me to correct some mistaken impressions which may have been conveyed by the remarks of some of the young doctors who took part in the conference of the Junior Members Forum of the B.M.A. (The Times, 10 April).

General practitioners in the National Health Service are independent contractors who have agreed to provide a service to thei patients 24 hours a day for 365 days each year. Unless they arrange with a fellow principal on the medical list of the executive council to provide care during their periods off call they carry the full responsibility for every'hing that is done on thoir beha'f.

The majority of doctors in London subscribe to a deputizing service, but they can only use this after they have obtained permission to use a particular service from the executive council, and this is normally given to a single-handed practitioner for a maximum of up to two nights a week, half days, and alternate weekends. Of the 1,461 doctors in Inner London who have the council's consent to use a deputizing service only 17 have, because of illness, been given consent to use the service in excess of the normal maximum, and my impression is that the majority use a service with responsibility and discretion.

Each of the medical directors of the three services in London is interviewed at intervals by members of the executive council and it is then decided whether or not permission will be given to doctors to use the service he offers.

Because practitioners themselves bear the full responsibility for the advice that a deputizing doctor gives on their behalf the local medical committee regards it as one of its prime responsibilities to maintain a high standard in deputizing services, which now in London compare very favourably with those provided-in the name of the B.M.A. -in other parts of the country. Each service now has a medical advisory committee elected by subscribers which meets regularly and inquires into any complaints which have been made and makes suggestion for the improvement of the service. Every member of the medical advisory committee is invited to visit the service at any time to observe the way in which it is being conducted.

M=mbers of the local medical committee attend the meetings of all the medical advisory committees. I have attended-perhaps more recently than Mr. F. J. Brambleinterviews of applicants to serve with deputizing services, and I have been impressed with the high standards which are required. Further convincing rebuttal of the allegations made at the young doctors' meeting is provided by the fact that of 50 complaints considered by the Inner London Executive Council last year only one-which was dismissed-concerned deputizing arrangements.

The person best qualified to assess the quality of a deputizing service is the family doctor who visits the patient the next morning and carries responsibility for what has been done. Through the local medical committee and the medical advisory committees he now has ready channels of communication which provide a mechanism for the immediate expression of any criticism or dissatisfaction. This provides a means of control arising from the point of delivery of the service, which is much more effective and much more rapid than any powers which might be given to the Secretary of State for Social Services by legislation.-I am, etc.,

DenIS R. CoOK Inner London Medical Committee

London W.C.1

\section{Verapamil in Cardiac Arrhythmias}

SIR,-I was interested to read Dr. L. Schamroth and colleagues' paper (11 March, p. 660) on the efficacy of verapamil in controlling supraventricular dysrhythmias. I noticed, however, there was no reference to its use in postinfarction dysrhythmias. Recently, I used this drug on two patients who were admitted to the coronary care unit at Edgware General Hospital.

A 63-year-old woman had a history of 